\title{
Bremia lactucae Infection Efficiency in Lettuce is Modulated by Temperature and Leaf Wetness Duration Under Quebec Field Conditions
}

\author{
M. L. Fall, Biology Department, University of Sherbrooke, Sherbrooke, QC, Canada J1K 2R1 and Horticulture Research and Development \\ Centre, Agriculture and Agri-Food Canada, St-Jean-sur-Richelieu, QC, Canada J3B 3E6; H. Van der Heyden, Compagnie de Recherche Phy- \\ todata Inc., Sherrington, QC, Canada J0L 2N0; C. Beaulieu, Biology Department, University of Sherbrooke; and O. Carisse, Horticulture
} Research and Development Centre, Agriculture and Agri-Food Canada

\begin{abstract}
Fall, M. L., Van der Heyden, H., Beaulieu, C., and Carisse, O. 2015. Bremia lactucae infection efficiency in lettuce is modulated by temperature and leaf wetness duration under Quebec field conditions. Plant Dis. 99:1010-1019.

More than $80 \%$ of Canadian lettuce production is located in the province of Quebec. Yet most of our knowledge on the epidemiology of lettuce downy mildew (Bremia lactucae) is derived from controlled-condition experiments or field experiments conducted in subtropical climates and, thus, cannot readily be applied to Quebec lettuce production. The influence of temperature and leaf wetness duration on the infection efficiency (IE) of B. lactucae was studied for 4 years (2003, 2004, 2012, and 2013) under field and growth-chamber conditions. IE was defined as the ratio of the number of lesions/leaf to the airborne conidia concentration (ACC). B. lactucae ACC was measured with rotating-arm samplers three times/week. In addition, 72 lettuce trap plants/sampling day were exposed to the potential airborne B. lactucae inoculum and disease intensity was assessed after 7 days of incubation in greenhouse. Under growthchamber conditions, an ACC of 1 conidium $/ \mathrm{m}^{3}$ was sufficient to cause

1 lesion/leaf, and IE ranged from 0.25 to 1.00 . Under field conditions, an ACC of 10 to 14 conidia $/ \mathrm{m}^{3}$ was required to cause 1 lesion/leaf, and IE ranged from 0.02 to 0.10 , except in 2004, when IE ranged from 0.03 to 1.00 . IE increased with increasing leaf wetness duration but decreased with increasing temperature. Also, considering an observed average temperature range from 10 to $20^{\circ} \mathrm{C}$ in the area of Quebec, $2 \mathrm{~h}$ of leaf wetness was sufficient for infection by B. lactucae. Therefore, under Quebec lettuce production conditions, a leaf wetness period of $2 \mathrm{~h}$ and an ACC of 10 to 14 conidia $/ \mathrm{m}^{3}$ can be used as risk indicators to facilitate disease management decisions. Also, under typical Quebec weather conditions, measuring both morning and evening leaf wetness events could be used to improve the reliability of leaf wetness duration as a downy mildew risk indicator. Further research is needed to validate these risk indicators for integration into management strategies.
\end{abstract}

Lettuce (Lactuca sativa) downy mildew, caused by the oomycete Bremia lactucae Regel, is a major threat in lettuce production worldwide (13). Spores of B. lactucae have lost the ability to form zoospores and germinate directly on a leaf surface (11). Thus, the term "conidia" is used in this study instead of "sporangia", although the latter term is used commonly in the literature $(7,21)$.

Despite the presence of the disease every year, outbreaks of lettuce downy mildew are typically sporadic and associated with specific environmental conditions (13). The potential risk of disease development and consequent yield losses also depend on the amount of $B$. lactucae conidia in lettuce fields. B. lactucae produces conidia that are adapted to aerial dispersal $(6,26)$. They are produced when relative humidity $(\mathrm{RH})$ is high and wind speed is low, and conidia release coincides with decreasing humidity and increasing temperature, conditions that generally occur in the morning (28). Viable conidia that are deposited on the leaf of a susceptible lettuce plant germinate and colonize the leaf, resulting in symptoms that are visible 8 to 14 days after the initiation of infection, depending on host susceptibility and environmental conditions $(17,19)$.

Environmental factors such as temperature, $\mathrm{RH}$, wind speed, solar radiation, and leaf wetness duration have been identified as factors that influence sporulation, dispersal, survival, and infection processes $(6,20,24,28,29)$. Hence, conidia survival is greater at 23 than at $31^{\circ} \mathrm{C}(2$ to $5 \mathrm{~h})$ at an $\mathrm{RH}$ between 33 and $76 \%$ whereas, at an $\mathrm{RH}$ $\geq 90 \%$, survival of conidia increases substantially (24,27). Wind speed plays a major role in the conidia dispersal process, and the amount of solar radiation affects the survival of the airborne conidia

Corresponding author: O. Carisse; E-mail: odile.carisse@agr.gc.ca

Accepted for publication 31 January 2015.

http://dx.doi.org/10.1094/PDIS-05-14-0548-RE

(C) 2015 The American Phytopathological Society
$(4,27)$. However, the most important factor for successful infection seems to be a duration of morning leaf wetness of at least 3 or $4 \mathrm{~h}$ $(8,10,16,23)$. Therefore, many forecasting systems for lettuce downy mildew use morning leaf wetness duration as an indicator for occurrence of an infection period $(10,16,18)$. In fact, according to the forecasting system developed by Scherm et al. (16) (and a modified version developed subsequently), infection by B. lactucae occurs on days when leaf wetness ends late in the morning (10:00 h) (16). The BREMCAST system developed in Quebec, Canada, by Kushalappa (10) considers a leaf wetness duration of 3 to $5 \mathrm{~h}$ after dawn (continuing until 10:00 h) to initiate fungicide application. These systems assume that sporulation is nocturnal, that conidia are released at dawn, and that infections occur in the morning $(10,16)$. However, in a study conducted in Quebec, Carisse and Philion (4) observed conidia release patterns during the afternoon on 21 and $17 \%$ of the days when spores were trapped. Moreover, Bhaskara Reddy et al. (2) observed that $>50 \%$ of conidia survived a solar radiation dose of 10 $\mathrm{MJ} / \mathrm{m}^{2}$ over a period of $3 \mathrm{~h}$ and that, on overcast days, up to $80 \%$ of those conidia were viable after $9 \mathrm{~h}$. Wu et al. (29) noted that a forecasting system using a threshold of morning leaf wetness lasting from 06:00 to 10:00 $\mathrm{h}$ missed some infection days, and suggested that a leaf wetness duration of $3 \mathrm{~h}$ may be long enough for conidia to germinate. Scherm and van Bruggen (17) also observed some infection under short wetness durations, such as $2 \mathrm{~h}$. Therefore, some major epidemiological questions have arisen from these observations, including the following: What proportion of daily conidia is released in the morning (until 10:00 h)? Can a large amount of conidia released after 10:00 $\mathrm{h}$ infect lettuce later in the day in the region of Quebec? What is the minimum leaf wetness duration required for infection under field conditions in this region? What are the environmental factors that modulate infection events?

One way of improving lettuce downy mildew forecasting systems is to consider the amount of inoculum available locally, in addition to leaf wetness duration (16). For example, for the oomycete Phytophthora infestans, spore sampling coupled with a disease-forecasting 
system is useful for targeting the optimal time to apply a diseasecontrol product $(5,14)$. For Botrytis leaf blight of onion, which is caused by Botrytis squamosa, the use of a fungicide spray program based on a threshold of 10 to $15 \mathrm{conidia} / \mathrm{m}^{3}$ made it possible to reduce fungicide application by 75 and $56 \%$, depending on years and trials (3). Carisse and Philion (4) also observed that fluctuations in the numbers of airborne conidia of Bremia lactucae followed fluctuations in disease severity.

The life cycle of B. lactucae can be divided into four distinct stages: sporulation, conidia release, conidia survival, and infection. Each of these processes has been studied independently $(10,16,25)$. However, to study the combined effects of these processes, infection efficiency (IE), defined as the ratio of the number of lesions/leaf to the airborne conidia concentration (ACC), should be considered. Indeed, IE combines components derived from the pathogen (sporulation and conidia release) with components derived from the host-pathogen interaction (infection of leaves). Therefore, IE is probably influenced by environmental factors such as leaf wetness, solar radiation, and temperature. Despite the large amount of scientific information available on lettuce downy mildew, no field studies have focused on B. lactucae IE and the ways in which environmental factors influence IE. Therefore, the aim of this research was to study the influence of environmental factors on the IE of B. lactucae under Quebec weather conditions. Specifically, the study objectives were to (i) assess the daily percentage of conidia that is released outside the morning period (06:00 to 10:00 h) and the reliability of using morning leaf wetness duration as a risk indicator under Quebec weather conditions, (ii) examine the relationship between the ACC of B. lactucae and the number of lesions/leaf (IE) under growth-chamber and field conditions, and (iii) assess the influence of selected weather parameters on IE.

\section{Materials and Methods}

Data collected: Pattern of daily ACC and relationship between leaf wetness duration and pattern of ACC. The experiment was conducted between 1 July and 20 September 1997, 1998, 2003, and 2004. Each year, a plot of 'Ithaca' lettuce was established in an organic soil at the Agriculture and Agri-Food Canada experimental farm in Ste-Clotilde, QC (latitude $45^{\circ} 10^{\prime} \mathrm{N}$, longitude $\left.73^{\circ} 40^{\prime} \mathrm{W}\right)$. Lettuce plants produced in a greenhouse by Les Serres Lefort (Ste-Clotilde, QC, Canada), were transplanted $0.3 \mathrm{~m}$ apart in the rows, with $0.35 \mathrm{~m}$ between rows. The plots measured 30 by $30 \mathrm{~m}$, for a total of 33 rows and 5,676 plants. A 7-day volumetric spore sampler (Burkard Manufacturing Co, Rickmansworth, Hertfordshire, UK) placed in the center of the plot was used to monitor ACC (4). The sampler was adjusted to sample air at 10 liters $/ \mathrm{min}$. Impaction tapes were coated with a thin layer of silicone grease before they were placed in the sampler. Conidia counts were performed with a microscope at $\times 250$ magnification and converted to conidia per cubic meter of air as follows: (number of conidia/rod $\times 1,000$ liters $/ \mathrm{m}^{3} / \mathrm{h}$ )/ (10 liters/min $\times 60 \mathrm{~min} / \mathrm{h} \times 1 \mathrm{~h})(4)$.

Relationship between ACC and number of lesions/leaf (IE), and the influence of selected weather parameters on IE. Growth-chamber trial. In a growth chamber (PGC20 growth chamber; Conviron, Winnipeg, MB, Canada), 20 lettuce plants (Ithaca) that had been produced in a greenhouse and had reached the six- to eight-leaf stage were placed $0.15 \mathrm{~m}$ apart in the chamber. Ten lettuce leaves with sporulating lesions were placed $1.25 \mathrm{~m}$ above the lettuce plants on a perforated shelf so that the plants were infected by falling airborne conidia in a manner similar to infection under field conditions (Fig. 1). The amount of inoculum was not controlled over the course of this experiment but, for each trial, an effort was made to provide the same number and size of sporulating lesions. To promote infection, the plants were held for $15 \mathrm{~h}$ in the dark, then for $9 \mathrm{~h}$ in light (growth-chamber fluorescent lamps, $150 \mu \mathrm{mol} / \mathrm{m}^{2} / \mathrm{s}$ ) at $18^{\circ} \mathrm{C}$ and $100 \% \mathrm{RH}$, with a leaf wetness period of $6 \mathrm{~h}$. After $24 \mathrm{~h}$, the sporulating leaves were removed and the growth chamber was maintained at $18^{\circ} \mathrm{C}$ and $90 \% \mathrm{RH}$ for 6 days, with a daily cycle of $9 \mathrm{~h}$ of darkness and $15 \mathrm{~h}$ of light. A rotating-arm spore sampler (Compagnie de Recherche Phytodata, Inc., Sherrington, QC, Canada) placed $0.5 \mathrm{~m}$ above the lettuce plants was used to monitor ACC in the growth chamber. The sampler was operated for $17.6 \mathrm{~h}$ per 24 -h sampling period (alternating between $11 \mathrm{~min}$ on and $4 \mathrm{~min}$ off), and the effective air-sampling rate was 21 liters/min. Conidia caught on the sampling surfaces (rods) were counted within $24 \mathrm{~h}$ after sampling with a microscope at $\times 250$ magnification. The number of conidia/rod was converted to conidia per cubic meter as follows: (number of conidia/rod $\left.\times 1,000 \mathrm{liters} / \mathrm{m}^{3} / \mathrm{h}\right) /(21 \mathrm{liters} / \mathrm{min} / \mathrm{rod} \times 60 \mathrm{~min} / \mathrm{h} \times 17.6 \mathrm{~h})$. This experiment was repeated 30 times. The number of lesions/leaf was assessed on all plants in the growth chamber by randomly selecting five leaves on each plant.

Field trial. In 2003, 2004, 2012, and 2013, a plot of Ithaca lettuce was established in an organic soil at the Agriculture and Agri-Food Canada experimental farm in Ste-Clotilde, QC. Lettuce plants produced in a commercial greenhouse by Les Serres Lefort were transplanted $0.3 \mathrm{~m}$ apart in the rows, with $0.35 \mathrm{~m}$ between rows. The plots measured 30 by $30 \mathrm{~m}$, for a total of 33 rows and 5,676 plants. In the lettuce plots each year, 72 lettuce trap plants (Ithaca) were placed randomly in the field each Tuesday, Wednesday, and Thursday for $24 \mathrm{~h}$ (total of 216 trap plants/week). The trap plants were divided into four trays $(0.135$ by $0.07 \mathrm{~m}$ and $0.04 \mathrm{~m}$ in depth) containing 18 plants each. The trap plants placed in the field over the course of the study were always at the same growth stage (five- to seven-leaf stage) and were produced in a greenhouse by Les Serres Lefort (Ste-Clotilde, QC, Canada). After $24 \mathrm{~h}$ of potential exposure to airborne B. lactucae inoculum in the field, the trap plants were incubated in a greenhouse for 7 days under $90 \% \mathrm{RH}$ and a temperature between 18 and $24^{\circ} \mathrm{C}$. After 7 days of incubation, disease severity was assessed as the number of lesions on five randomly selected leaves/plant, excluding leaves that had emerged after exposure in the field. Trap plants were exposed to the potential inoculum release 47 times in 2003, 60 times in 2004, 24 times in 2012, and 23 times in 2013 (for a total of 154 times). While the trap plants were exposed to naturally occurring airborne B. lactucae inoculum, ACC was monitored with three rotatingarm spore samplers with retracting sampling heads (Compagnie de Recherche Phytodata Inc.). Each sampler was supported $1.5 \mathrm{~m}$ off the ground by a pole, and the three poles were positioned in the center of the plot in a triangular pattern. Conidia counts were performed with a microscope at $\times 250$ magnification and converted to conidia per cubic meter of air as follows: (number of conidia/rod $\times 1,000$ liters $\left./ \mathrm{m}^{3} / \mathrm{h}\right) /(21$ liters $/ \mathrm{min} / \mathrm{rod} \times 60 \mathrm{~min} / \mathrm{h} \times 4.5 \mathrm{~h})$.

Measurement of environmental variables. Leaf wetness duration was assessed every minute by means of an electricalimpedance leaf-wetness sensor (Model 237; Campbell Scientific, Edmonton, AB, Canada) placed at the height of the lettuce leaves. Air temperature $\left({ }^{\circ} \mathrm{C}\right)$ and $\mathrm{RH}(\%)$ were monitored using WatchDog data loggers (Spectrum Technologies, Aurora, IL) located near the spore samplers. Weather variables were monitored every $30 \mathrm{~min}$, and hourly averages were used in the analyses. Temperature and $\mathrm{RH}$ probes were placed in a white shelter $1.5 \mathrm{~m}$ above the ground. Solar radiation data were obtained from an Environment Canada weather station located approximately $200 \mathrm{~m}$ from the plots.

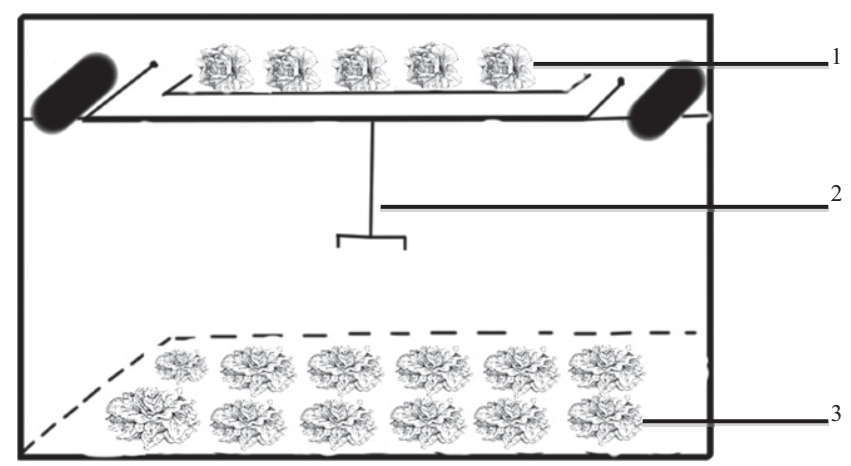

Fig. 1. Diagram illustrating the growth-chamber set-up for evaluating infection of lettuce plants by the downy mildew pathogen, Bremia lactucae. 1, Sporulating lettuce leaves; 2, Bremia lactucae airborne inoculum sampler (Compagnie de Recherche Phytodata Inc., Sherrington, QC, Canada); and 3, healthy Ithaca lettuce plants. 
Data analysis. First, normality of the data was tested using the Shapiro-Wilk test and then, if necessary, logarithmic transformation was done to improve normality. All statistical tests were performed in $\mathrm{R}$ version 3.0.0, as described below.

Pattern of daily ACC and relationship between leaf wetness duration and pattern of ACC. Airborne conidia pattern. Graphical representations of daily ACC released between 06:00 and 10:00 h as a function of day of the year in 1997, 1998, 2003, and 2004 were prepared. Scherm and van Bruggen (16) observed that B. lactucae conidia release in coastal California was initiated at sunrise $(06: 00 \mathrm{~h})$ and that infection occurred within a 3- to 4-h leaf wetness duration after sunrise. Each graphical representation for this study shows the daily ACC released during the period of 06:00 to 10:00 $\mathrm{h}$ in comparison with the total daily ACC for a 24-h sampling period, as well as the proportion of daily ACC that was released between 06:00 and 10:00 h. For each year, the percentages of daily conidia released during and outside the period of 06:00 to 10:00 $\mathrm{h}$ were calculated. The percentages of conidia released between 06:00 and 14:00 h were also calculated for each year.

Relationship between leaf wetness duration and airborne conidia pattern. A graphical representation of ACC and number of leaf wetness events as a function of time (4-h intervals) was prepared for the data from all 4 years $(1997,1998,2003$, and 2004). A period of at least three consecutive hours of leaf wetness was considered a leaf wetness event $(10,16,23)$. According to the hypothesis of Scherm and van Bruggen (17), regardless of the amount of inoculum, infection occurs on days when leaf wetness ends late in the morning (between 06:00 and 10:00 h). Thus, time was expressed in 4-h intervals. Fig. 2 shows the number of leaf wetness events in comparison with the ACC during the same period. The percentage of leaf wetness events that occurred between 22:00 and 06:00, 06:00 and 10:00, and 10:00 and 22:00 $\mathrm{h}$ were also calculated.

To assess the reliability of using a leaf wetness duration of 3 to $4 \mathrm{~h}$ as an indicator of infection by B. lactucae under Quebec weather conditions, a contingency table was calculated based on a 3-h threshold for leaf wetness duration. Each sampling date (24 h) in 2003 and 2004 was divided into six 4-h periods (02:00 to $06: 00,06: 00$ to $10: 00,10: 00$ to $14: 00,14: 00$ to $18: 00,18: 00$ to $22: 00$, and $22: 00$ to $02: 00 \mathrm{~h}$ ). For the contingency table, three periods of the day were considered. The period between 06:00 and 10:00 h was considered the standard in accordance with the Scherm and van Bruggen hypothesis (17). The periods between 10:00 and 14:00 $\mathrm{h}$ and 18:00 and 22:00 $\mathrm{h}$ were also taken into account because the ACC and number of leaf wetness events were considerable during those periods (Fig. 2). For each of these three periods, a leaf wetness duration $\geq 3 \mathrm{~h}$ was considered to be a prediction of the presence of lettuce downy mildew $(\mathrm{P}+)$ on trap plants, and a leaf wetness duration $<3 \mathrm{~h}$ was considered to be a prediction of the absence of this disease $(\mathrm{P}-)$. For each sampling day, the presence of downy mildew on trap plants was indicated by $\mathrm{O}+(\mathrm{ob}-$ served) and the absence of disease was indicated by $\mathrm{O}-$ (not observed). Therefore, there were four possible outcomes. First, disease was predicted $(\mathrm{P}+)$ and observed $(\mathrm{O}+)$. This situation was termed a "true positive" (TP). Second, disease was not predicted ( $\mathrm{P}-$ ) and was not observed (O-), termed a "true negative" (TN). Third, disease was predicted $(\mathrm{P}+)$ but was not observed $(\mathrm{O}-)$, termed a "false positive" (FP). Fourth, disease was not predicted $(\mathrm{P}-)$ but was observed $(\mathrm{O}+)$, termed a "false negative" (FN). The proportion of true positives was considered the indicator sensitivity $[\mathrm{TP} /(\mathrm{TP}+\mathrm{FN})]$. The proportion of true negatives was considered the indicator specificity $[\mathrm{TN} /(\mathrm{TN}+\mathrm{FP})]$. Overall accuracy was calculated as the number of correct assessments $(\mathrm{TN}+\mathrm{TP})$ divided by the number of all assessments $(\mathrm{TP}+\mathrm{TN}+\mathrm{FP}+$ $\mathrm{FN})$. The likelihood ratio of positive predictions (LR+) was estimated by $\mathrm{LR}+=$ sensitivity/( 1 - specificity $)$, and the likelihood ratio of negative predictions (LR-) was estimated by $\mathrm{LR}-=(1-$ sensitivity $) /$ specificity $(9,12)$.

Relationship between ACC and number of lesions/leaf. Growth-chamber trial. A scatter plot was prepared to represent the number of lesions/leaf as a function of ACC. A linear function was fitted to the data, as follows:

$$
y=\beta_{0}+\beta_{1} x
$$

where $y$ is the number of lesions/leaf, $x$ is the ACC, $\beta_{0}$ is the intercept parameter, and $\beta_{1}$ is the slope.

Field trial. Scatter plots representing the number of lesions/leaf as a function of ACC were prepared for the data from 2003, 2004, 2012, and 2013 separately and for the data from all four of these years. A three-parameter sigmoid model was fitted to these data as follows:

$$
y=\frac{a}{1+e^{-\left(\frac{x-x_{0}}{b}\right)}}
$$

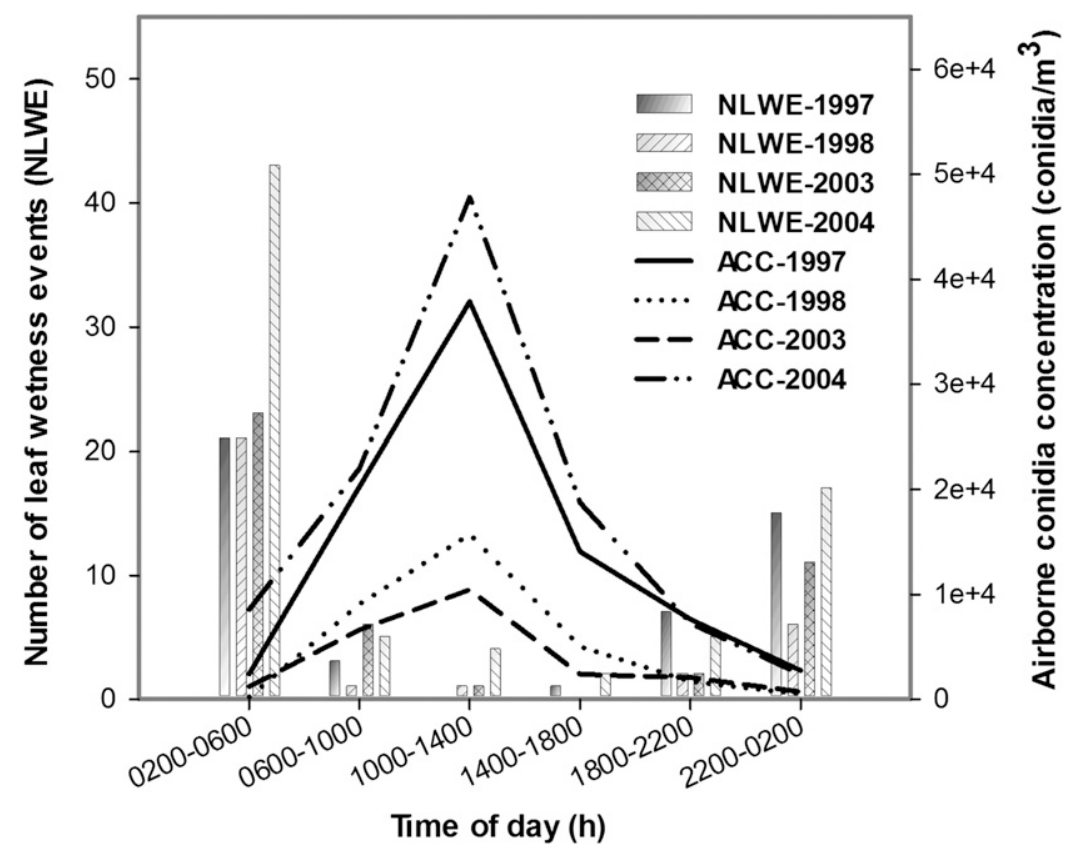

Fig. 2. Number of lettuce leaf wetness events (NLWE) and Bremia lactucae airborne conidia concentration (ACC) as a function of 4-h intervals. A period of at least three consecutive hours of leaf wetness was considered a leaf wetness event $(10,16,24)$. This study was done in field at the Agriculture and Agri-Food Canada experimental farm in Ste-Clotilde, in Quebec, Canada in 1997, 1998, 2003, and 2004. 


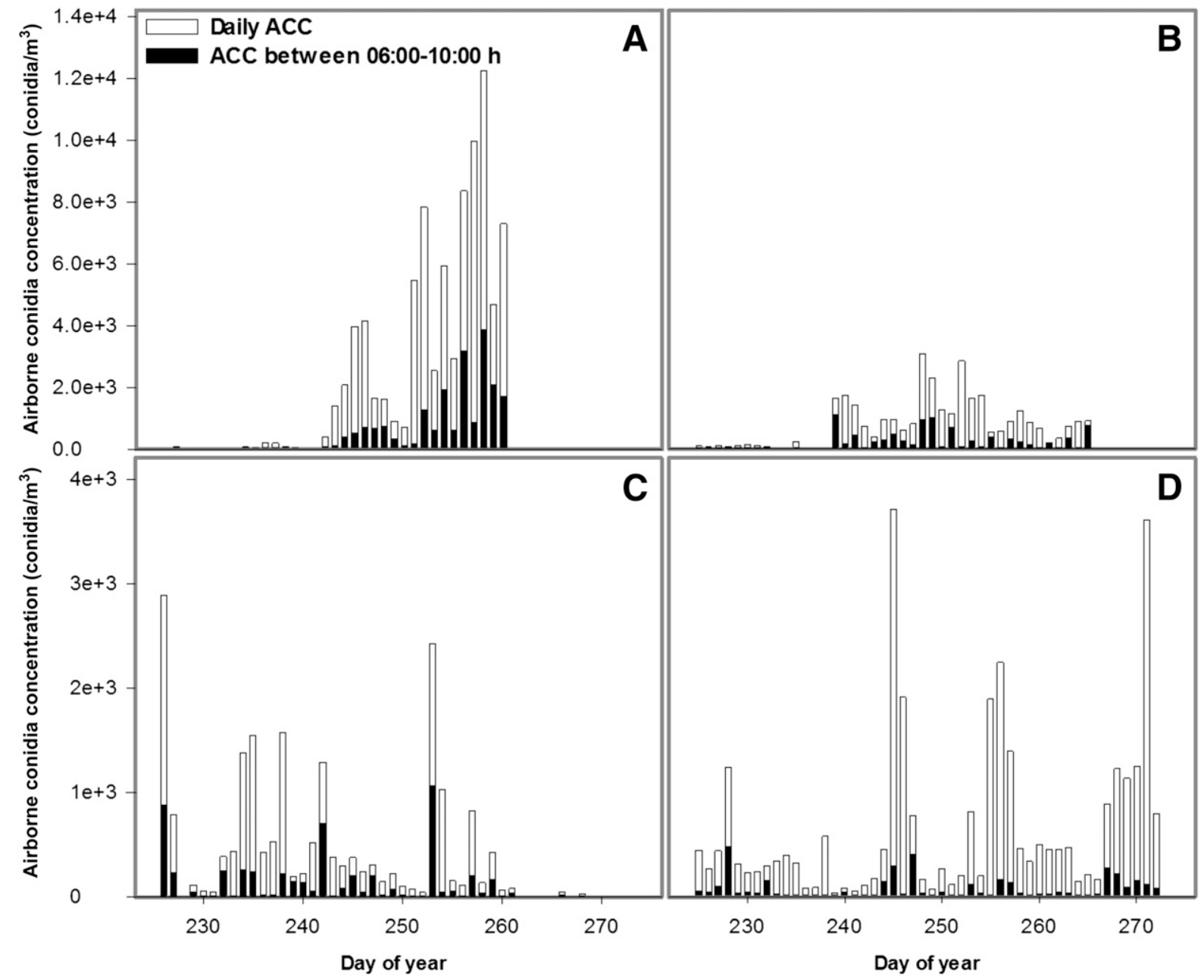

Fig. 3. Daily airborne conidia concentration (ACC) of Bremia lactucae as a function of day of the year (where day 1 is 1 January) in A, 1997; B, 1998; C, 2003; and D, 2004. The term "Total daily ACC" represents the ACC for a 24-h sampling period. This study was done in lettuce crops at the Agriculture and Agri-Food Canada experimental farm in Ste-Clotilde, Quebec, Canada.

Table 1. Contingency table for assessment of the reliability of using a leaf wetness duration of 3 to $4 \mathrm{~h}$ as an indicator of infection of the lettuce plants by Bremia. lactucae under field conditions in field at the Agriculture and Agri-Food Canada experimental farm in Ste-Clotilde, Quebec, Canada

\begin{tabular}{|c|c|c|c|c|c|c|c|c|c|}
\hline \multirow[b]{2}{*}{ Infection period $^{a}$} & \multirow[b]{2}{*}{ Observed } & \multicolumn{2}{|c|}{ Predicted } & \multirow[b]{2}{*}{ Total } & \multirow[b]{2}{*}{ Overall accuracy $^{\mathbf{b}}$} & \multirow[b]{2}{*}{ Sensitivity ${ }^{\mathbf{b}}$} & \multirow[b]{2}{*}{ Specificity $^{b}$} & \multirow[b]{2}{*}{$\mathbf{L R}+^{\mathrm{c}}$} & \multirow[b]{2}{*}{ LR-c } \\
\hline & & $\mathbf{P}+$ & $\mathbf{P}-$ & & & & & & \\
\hline \multirow[t]{3}{*}{ 06:00-10:00 h (T1) } & $\mathrm{O}+$ & 15 & 23 & 38 & 0.545 & 0.395 & 0.882 & 3.00 & 0.69 \\
\hline & $\mathrm{O}-$ & 2 & 15 & 17 & $\ldots$ & $\ldots$ & $\ldots$ & $\ldots$ & $\ldots$ \\
\hline & Total & 17 & 38 & 55 & $\ldots$ & $\ldots$ & $\ldots$ & $\ldots$ & $\ldots$ \\
\hline \multirow[t]{3}{*}{ 10:00-14:00 h (T2) } & $\mathrm{O}+$ & 2 & 36 & 38 & 0.317 & 0.053 & 0.941 & 0.89 & 1.01 \\
\hline & $\mathrm{O}-$ & 1 & 16 & 17 & $\ldots$ & $\ldots$ & $\ldots$ & $\ldots$ & $\ldots$ \\
\hline & Total & 3 & 52 & 55 & $\ldots$ & $\ldots$ & $\ldots$ & $\ldots$ & $\ldots$ \\
\hline \multirow[t]{3}{*}{ 18:00-22:00 h (T3) } & $\mathrm{O}+$ & 5 & 33 & 38 & 0.382 & 0.132 & 0.941 & 2.24 & 0.92 \\
\hline & $\mathrm{O}-$ & 1 & 16 & 17 & $\ldots$ & $\ldots$ & $\ldots$ & $\ldots$ & $\ldots$ \\
\hline & Total & 6 & 49 & 55 & $\ldots$ & $\ldots$ & $\ldots$ & $\ldots$ & $\ldots$ \\
\hline \multirow[t]{6}{*}{$\mathrm{T} 1+\mathrm{T} 3$} & $\mathrm{O}+$ & 26 & 12 & 38 & 0.709 & 0.684 & 0.765 & 2.91 & 0.41 \\
\hline & $\mathrm{O}-$ & 4 & 13 & 17 & $\ldots$ & $\ldots$ & $\ldots$ & $\ldots$ & $\ldots$ \\
\hline & Total & 30 & 25 & 55 & $\ldots$ & $\ldots$ & $\ldots$ & $\ldots$ & $\ldots$ \\
\hline & $\mathrm{O}+$ & 26 & 12 & 38 & $\ldots$ & $\ldots$ & $\ldots$ & $\ldots$ & $\ldots$ \\
\hline & $\mathrm{O}-$ & 4 & 13 & 17 & $\ldots$ & $\ldots$ & $\ldots$ & $\ldots$ & $\ldots$ \\
\hline & Total & 30 & 25 & 55 & $\ldots$ & $\ldots$ & $\ldots$ & $\ldots$ & $\ldots$ \\
\hline
\end{tabular}

a For each of the infection periods $\mathrm{T} 1, \mathrm{~T} 2, \mathrm{~T} 3$, and $\mathrm{T} 1+\mathrm{T} 3$, a leaf wetness duration of $\geq 3 \mathrm{~h}$ was considered to be a prediction of the presence of downy mildew $(\mathrm{P}+)$ on lettuce trap plants, and a leaf wetness duration $<3 \mathrm{~h}$ was considered a prediction of the absence of downy mildew $(\mathrm{P}-)$. For each sampling day, the presence of lesions on trap plants was indicated by $\mathrm{O}+$ (observed), and the absence of lesions was indicated by $\mathrm{O}-$ (not observed).

b The proportion of true positives $(\mathrm{O}+$ and $\mathrm{P}+$ ) was regarded as a measure of sensitivity, the proportion of true negatives $(\mathrm{O}-$ and $\mathrm{P}-$ ) as specificity, and the overall accuracy was calculated as the number of correct assessments $(\mathrm{O}+$ and $\mathrm{P}+$, and $\mathrm{O}-$ and $\mathrm{P}-$ ) divided by the number of all assessments $(9)$.

${ }^{c} \mathrm{LR}+$ and $\mathrm{LR}-=$ positive likelihood ratio and negative likelihood ratio, respectively; $\mathrm{LR}+=$ sensitivity/( $1-$ specificity $)$ and LR $-=(1-$ sensitivity $) /$ specificity $(12)$. 
where $y$ is the number of lesions/leaf, $a$ is the asymptote, $x_{0}$ is the $\mathrm{ACC}$ at the inflection point where the number of lesions/leaf is $50 \%$ of the asymptote, and $b$ is the slope of the linear portion of the curve. The model appropriateness and goodness of fit to the data were assessed using an adjusted $R^{2}$ and a concordance correlation coefficient (12).

Relationship between IE and weather parameters under field conditions. Correlations among IE and selected weather variables were analyzed using Spearman's rank correlation matrix in $\mathrm{R}$ (Hmisc package 3.4.0). For each sampling date, the average temperature (TPa), maximum solar radiation (SR), and leaf wetness duration (LWD) were considered.

Binary recursive partitioning in the $\mathrm{R}$ tree package was used to build a classification tree for IE (15). This process successively split the data along coordinate axes of explanatory variables so that, at any node, the split which maximally distinguished the response variable in the left and right branches was selected. Each explanatory variable (TPa, SR, and LWD) was assessed in turn, and the variable explaining the greatest amount of deviance in IE was selected. The smallest permitted node was 10 , and the node was not partitioned if the within deviance was $\leq 0.01$ of the root node (15). The two explanatory variables explaining the greatest amount of deviance in IE were used to plot the classification tree using the partition.tree function. To construct the partition plot, IE was transformed into a binary variable where IE values of $\geq 0.1$ ( 1 lesion/leaf $/ 10$ conidia $/ \mathrm{m}^{3}$ ) were coded as "ls" (lesion) or "nls" (no lesion). IE values between 0.056 and 0.099 were rounded to 0.1 .

\section{Results}

Pattern of daily ACC and relationship between leaf wetness duration and pattern of ACC. Most conidia were released outside the period between 06:00 and 10:00 h (Figs. 2 and 3). On 91, 95, 90, and $92 \%$ of the sampling days, conidia released between 06:00 and 10:00 $\mathrm{h}$ accounted for $<50 \%$ of the conidia released daily in 1997, 1998, 2003, and 2004, respectively (Fig. 3). The maximum ACC was $12,236,2,136,2,885$, and 3,707 in 1997, 1998, 2003, and 2004, respectively (Fig. 3). The percentage of conidia released between 06:00 and 14:00 $\mathrm{h}$ was $70,76,73$, and $71 \%$ of the total conidia released daily in 1997, 1998, 2003, and 2004, respectively (Fig. 2).

In 1997, 76.6, 6.4, and $17.0 \%$ of all leaf wetness events occurred between 22:00 and 06:00, 06:00 and 10:00, and 10:00 and 22:00 h, respectively (Fig. 2). In 1998, 90, 3.3, and 6.7\% of all leaf wetness events occurred between 22:00 and 06:00, 06:00 and 10:00, and 10:00 and 22:00 h, respectively. In 2003, 79, 14, and 7\% of all leaf wetness events occurred between 22:00 and 06:00, 06:00 and 10:00, and 10:00 and 22:00 h, respectively. In 2004, 79, 6.5, and $14.5 \%$ of all leaf wetness events occurred between 22:00 and 06:00, 06:00 and 10:00, and 10:00 and 22:00 h, respectively. According to the data from all 4 years together, $80 \%$ of all leaf wetness events occurred between 22:00 and 06:00 h, 7\% between 06:00 and 10:00 h, 13\% between 10:00 and 22:00 h, and 8.5\% between 18:00 and 22:00 $\mathrm{h}$. In addition, the greatest daily ACCs were detected between 06:00 and 14:00 h (Fig. 2).
The overall accuracy of using a leaf wetness duration $\geq 3 \mathrm{~h}$ as a lettuce downy mildew risk indicator was greater when morning (06:00 to $10: 00 \mathrm{~h}$ ) leaf wetness was used than when evening (18:00 to 22:00 h) leaf wetness was used (accuracy of 0.545 versus 0.382 ). Using only morning leaf wetness led to $39.5 \%$ of downy mildew infections being predicted (sensitivity $=0.395$ ). In contrast, using both morning and evening leaf wetness as a downy mildew risk indicator led to $68.4 \%$ of downy mildew infections being predicted. Also, using both morning and evening leaf wetness did not increase the likelihood ratio of positive prediction of downy mildew but decreased the likelihood ratio of negative prediction of downy mildew (Table 1). However, using leaf wetness events between 10:00 and 14:00 h (Table 1, T2), morning leaf wetness events (between 06:00 and 10:00 h; Table 1, T1), and evening leaf wetness events (between 18:00 and 22:00 h; Table 1, T3) did not improve the accuracy and sensitivity of the downy mildew risk indicator compared with using the combination of morning leaf wetness and evening leaf wetness (Table 1, T1 + T3).

Relationship between ACC and number of lesions/leaf. Growth-chamber trial. The number of lesions/leaf was directly proportional to ACC (Fig. 4). An ACC of 1 conidium $/ \mathrm{m}^{3}$ was sufficient to cause 1 lesion/leaf based on the regression equation shown in Figure 4.

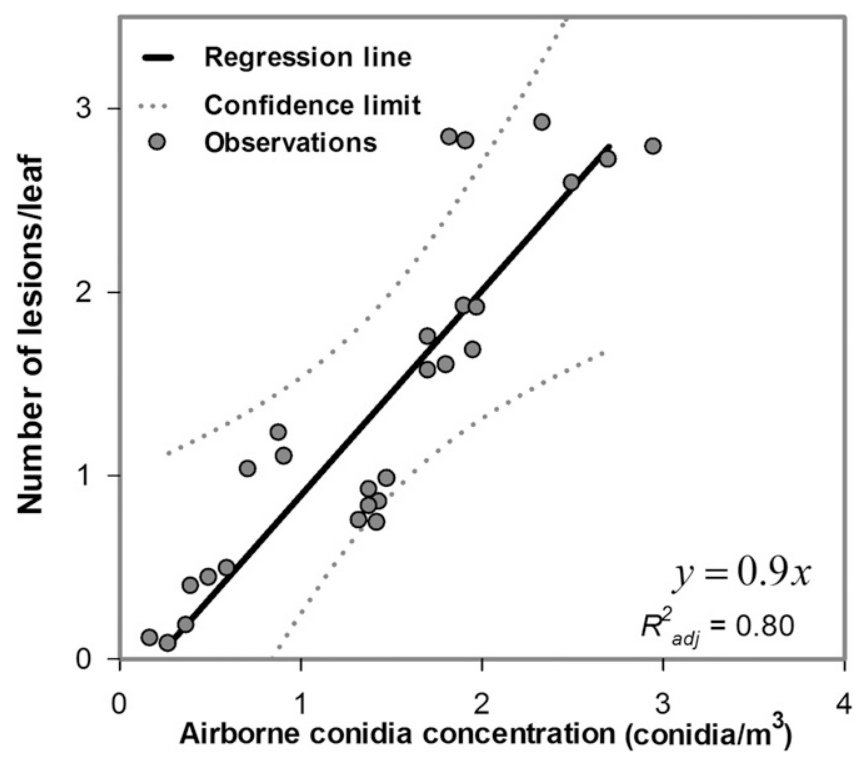

Fig. 4. Relationship between the number of downy mildew lesions/lettuce leaf and Bremia lactucae airborne conidia concentration under controlled conditions in a growth chamber (refer to main text for details on growth-chamber conditions and lettuce inoculation protocol). This study was done in Quebec, Canada. The solid straight line represents the fitted linear function and dotted lines represent the confidence interval. Each data point represents the mean number of lesion per leaf and the airborne conidia concentration.

Table 2. Estimated three-parameter sigmoidal regression models describing the relationship between the number of downy mildew lesions/leaf and Bremia lactucae airborne conidia concentration under field conditions in field at the Agriculture and Agri-Food Canada experimental farm in Ste-Clotilde, Quebec, Canada

\begin{tabular}{|c|c|c|c|c|c|c|}
\hline Year & $a^{\mathbf{a}}$ & $P^{\mathbf{b}}$ & $b^{\mathbf{c}}$ & $P^{d}$ & $x_{0}{ }^{\mathrm{e}}$ & $P^{f}$ \\
\hline 2003 & $22.96(0.80)$ & $<0.0001$ & $39.76(2.03)$ & $<0.0001$ & $122.80(3.85)$ & $<0.0001$ \\
\hline 2004 & $20.24(0.48)$ & $<0.0001$ & $35.46(2.14)$ & $<0.0001$ & $117.47(3.35)$ & $<0.0001$ \\
\hline 2012 & $12.39(3.16)$ & 0.0008 & $18.99(4.78)$ & 0.0007 & $118.34(6.97)$ & $<0.0001$ \\
\hline 2013 & $15.73(0.38)$ & $<0.0001$ & $71.43(6.45)$ & $<0.0001$ & $121.62(6.80)$ & $<0.0001$ \\
\hline $2003+2004+2012+2013$ & $19.29(0.36)$ & $<0.0001$ & $31.42(1.60)$ & $<0.0001$ & $116.75(2.43)$ & $<0.0001$ \\
\hline
\end{tabular}

a Asymptote of the three-parameter sigmoid model, number in parentheses $=$ standard error.

b Probability that $a$ is significantly different from 0 at $\alpha=0.05$.

c Slope of the linear portion of the curve.

d Probability that $b$ is significantly different from 0 at $\alpha=0.05$.

e Airborne conidia concentration at the inflection point where the number of lesions/leaf $=50 \%$ of the asymptote.

${ }^{\mathrm{f}}$ Probability that $x_{0}$ is significantly different from 0 at $\alpha=0.05$. 


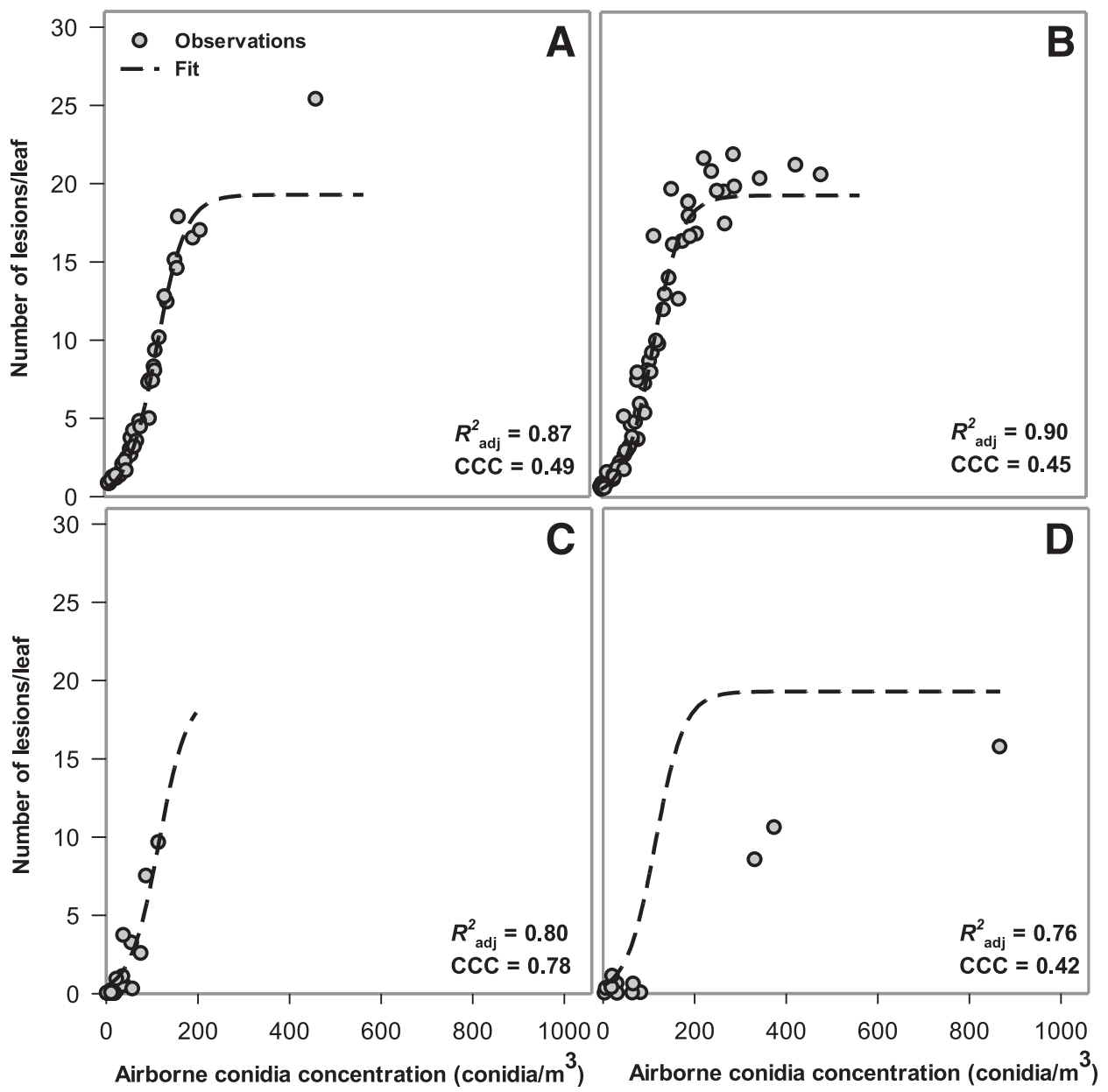

Fig. 5. Relationship between the number of downy mildew lesions/lettuce leaf and Bremia lactucae airborne conidia concentration under field conditions in A, 2003; B, 2004; C, 2012; and D, 2013. A three-parameter sigmoidal model was fitted with the same shape parameter for each year (see equation 2 in the main text). CCC = concordance correlation coefficient, a measure of model appropriateness and goodness of fit (12), and $R^{2}$ adj $=$ adjusted coefficient of determination. The study was done in a field at the Agriculture and Agri-Food Canada experimental farm in Ste-Clotilde, Quebec, Canada. Each data point represents the mean number of lesion per leaf and the airborne conidia concentration.

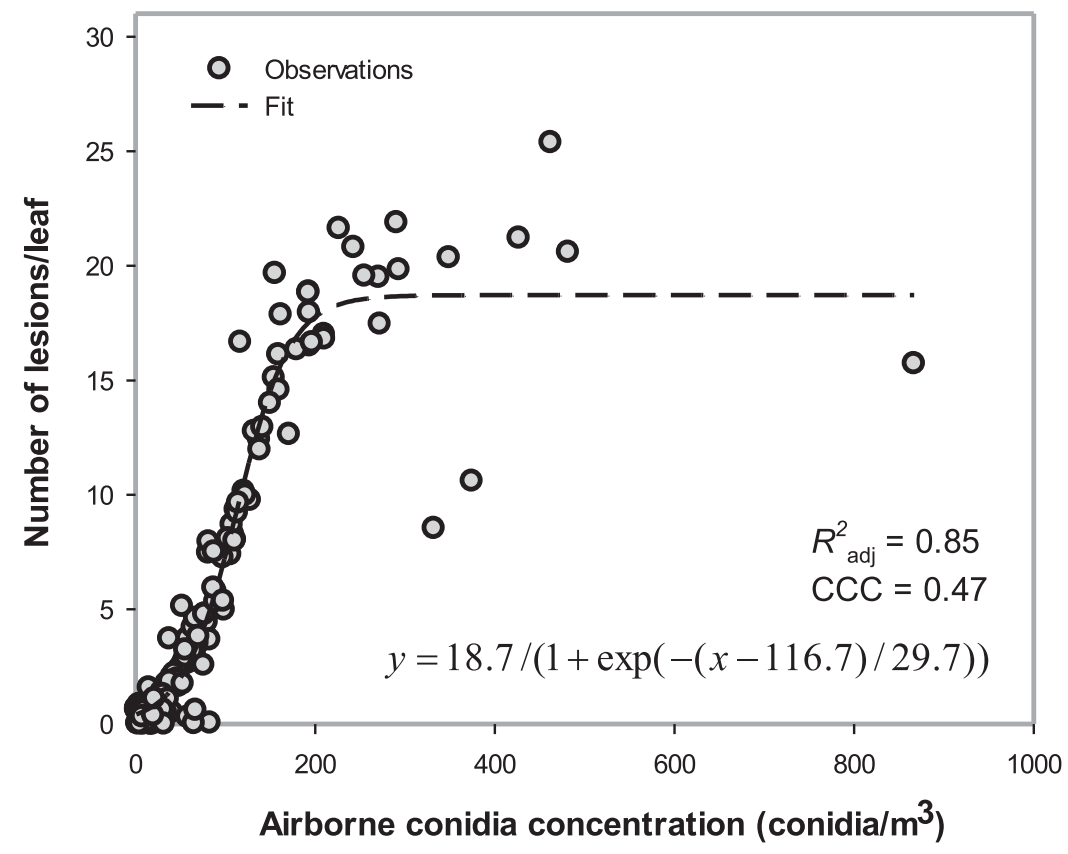

Fig. 6. Relationship between the number of downy mildew lesions/lettuce leaf and Bremia lactucae airborne conidia concentration under field conditions for the data pooled from 4 years $(2003,2004,2012$, and 2013). A three-parameter sigmoid model was fitted to the data (see equation 2 in the main text). CCC = concordance correlation coefficient, a measure of model appropriateness and goodness of fit (12), and $R^{2}$ adj $=$ adjusted coefficient of determination. The study was done in a field at the Agriculture and AgriFood Canada experimental farm in Ste-Clotilde, Quebec, Canada. Each data point represents the mean number of lesion per leaf and the airborne conidia concentration. 
Field trial. The $x_{0}$, which is an estimate of the ACC at the inflection point that corresponds to the number of lesions/leaf at $50 \%$ of the maximum (asymptote), was $122.80 \pm 3.85,117.46( \pm 3.35), 118.33 \pm$ 6.97, and $121.62 \pm 6.80$ conidia $/ \mathrm{m}^{3}$ in $2003,2004,2012$, and 2013, respectively (Table 2; Fig. 5). When the data from all 4 years were pooled, $116.75 \pm 2.43$ conidia $/ \mathrm{m}^{3}$ were required to achieve $50 \%$ of the maximum number of lesions/leaf (20 lesions) (Table 2; Fig. 6). According to a sigmoidal regression model (Fig. 6), an ACC of 14 conidia $/ \mathrm{m}^{3}$ was sufficient to cause 1 lesion/leaf. The sigmoidal model for all 4 years in Figure 6 consisted of three phases: a quasilinear phase between 0 and 15 lesions/leaf, in which the number of lesions/leaf was proportional to the ACC; a deceleration phase between 15 and 20 lesions/leaf; and a stationary phase of about 20 lesions/leaf, in which the number of lesions did not change even though the ACC increased (Fig. 6).

Relationship between IE and selected weather parameters. Under controlled conditions in the growth-chamber trials, IE ranged from 0.250 to 1.000 ; whereas, under field conditions, IE ranged from

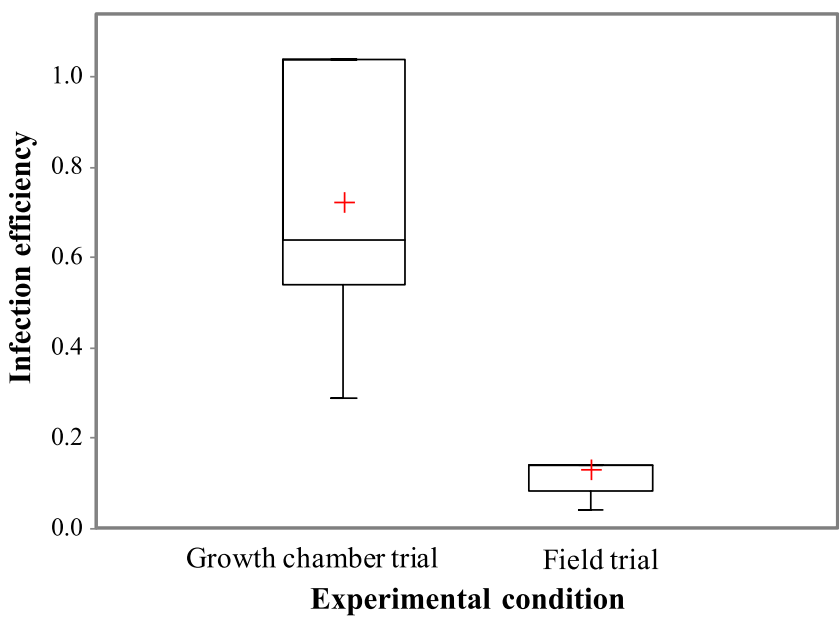

Fig. 7. Bremia lactucae infection efficiency (IE) on plants of Ithaca lettuce under growth-chamber conditions and field conditions at the Agriculture and Agri-Food Canada experimental farm in Ste-Clotilde, Quebec, Canada, with $n=30$ plants in the growth-chamber trial, and $n=154$ for trap plants in the field trials. IE was defined as the ratio of the number of lesions/leaf to the airborne conidia concentration (see the main text for details on the growth-chamber conditions and the lettuce inoculation protocol). The "whiskers" of the box plots represent the lower quartile, " + " sign represents the mean value, and horizontal line inside box plots represents the median value.
0.034 to 0.100 in $2003,0.033$ to 1.000 in $2004,0.000$ to 0.100 in 2012, and 0.000 to 0.023 in 2013 (Fig. 7). Some weather parameters had significant associations with $B$. lactucae IE under field conditions. For all 4 years, IE increased as LWD increased (Table 3) whereas, for all years except 2003, IE decreased as daily TPa increased; in 2003, there was no significant association between the TPa and IE (Table 3). Overall, the TPa association with IE was weak (correlation coefficients of $0.00,-0.06,-0.62$, and -0.06 in 2003 , 2004, 2012, and 2013, respectively), and SR did not show significant association with IE except in 2004 (correlation coefficient was -0.60 and $P=0.04$; Table 3 ). LWD was associated significantly with IE measured in all years, and TPa had limited association with IE (Table 3; Fig. 8). There was an exponential relationship between IE and LWD, with $120 \mathrm{~min}(2 \mathrm{~h})$ of leaf wetness being sufficient to cause an IE of 0.1 (Fig. 8). Under field conditions, $2 \mathrm{~h}$ of LWD and an ACC of 10 conidia $/ \mathrm{m}^{3}$ were needed to cause 1 lesion/leaf as long as the $\mathrm{TPa}$ was $<20^{\circ} \mathrm{C}$ (Fig. 9). A leaf wetness duration of $\geq 180 \mathrm{~min}(3 \mathrm{~h})$ caused at least 1 lesion per leaf even at temperatures between 20 and $25^{\circ} \mathrm{C}$. Temperatures $\geq 26^{\circ} \mathrm{C}$ were not tested in this study (Fig. 9).

\section{Discussion}

The majority of Canadian lettuce production is located in the province of Quebec (1) and, each year, downy mildew caused by B. lactucae occurs in this area (4). However, information on the epidemiology of $B$. lactucae is derived primarily from controlledcondition experiments or field experiments conducted in subtropical climates and, therefore, cannot readily be applied to Quebec lettuce production $(2,13,17-20,23,24,27)$. Even though considerable efforts have been made to develop downy-mildew-resistant lettuce cultivars, no cultivar is resistant at all growth stages (seeding, young plant, and mature plant) and to all races of B. lactucae to avoid losses for growers (22). Therefore, efficient control of lettuce downy mildew currently depends on a good understanding of the epidemiology of B. lactucae and on implementing appropriate control measures. Moreover, lettuce is a short-season crop (45 to 55 days in Quebec) and, on farms with successive plantings of lettuce each season, as in Quebec, the potential risk of downy mildew and consequent yield losses is affected by inoculum build-up over the season. Therefore, the main purpose of this study was to investigate the relationship between B. lactucae airborne inoculum and downy mildew severity under Quebec weather conditions, and the ways in which environmental factors influence this relationship.

In Quebec lettuce production systems, the assumption (as a result of studies on the disease in other climates and regions) that infection by $B$. lactucae occurs only between 06:00 and 10:00 h has meant that

Table 3. Correlation matrix for infection efficiency (IE) of the lettuce downy mildew pathogen Bremia lactucae, average daily air temperature (TPa), solar radiation (SR), and leaf wetness duration (LWD) ${ }^{\mathrm{a}}$

\begin{tabular}{|c|c|c|c|c|}
\hline Year & Variable & $\operatorname{TPa}\left({ }^{\circ} \mathbf{C}\right)^{\mathbf{b}}$ & $\operatorname{SR}\left(K J / \mathbf{m}^{2}\right)^{\mathbf{b}}$ & LWD $(\min )^{\mathbf{b}}$ \\
\hline \multirow[t]{3}{*}{2003} & $\mathrm{IE}$ & 0.00 & -0.03 & $0.76^{* * *}$ \\
\hline & LWD & 0.00 & -0.17 & $\ldots$ \\
\hline & SR & 0.26 & $\ldots$ & $\ldots$ \\
\hline \multirow[t]{3}{*}{2004} & IE & $-0.06^{*}$ & 0.25 & $0.66^{* * *}$ \\
\hline & LWD & $-0.05^{*}$ & 0.25 & $\ldots$ \\
\hline & SR & 0.04 & $\ldots$ & $\ldots$ \\
\hline \multirow[t]{3}{*}{2012} & IE & $-0.62 *$ & $-0.60^{*}$ & $0.72 * * *$ \\
\hline & LWD & $-0.28 * * \mathrm{f}$ & -0.49 & $\ldots$ \\
\hline & SR & 0.36 & $\ldots$ & $\ldots$ \\
\hline \multirow[t]{3}{*}{2013} & IE & $-0.06^{*}$ & -0.21 & $0.68 * * *$ \\
\hline & LWD & -0.39 & -0.35 & $\ldots$ \\
\hline & SR & $-0.04 *$ & $\ldots$ & $\ldots$ \\
\hline \multirow[t]{3}{*}{$2003+2004+2012+2013$} & IE & $-0.48^{*}$ & 0.19 & $0.84 * * *$ \\
\hline & LWD & -0.33 & 0.06 & $\ldots$ \\
\hline & SR & $-0.16^{*}$ & $\ldots$ & $\ldots$ \\
\hline
\end{tabular}

a This study was done in field at the Agriculture and Agri-Food Canada experimental farm in Ste-Clotilde, Quebec, Canada. IE = the ratio of the number of lesions/ leaf to the airborne conidia concentration. Refer to main text for details on measurement of the variables TPa, SR, and LWD.

b Asterisks: $* * * * *$, and $*$ indicate $P<0.001,0.01$, and 0.05 , respectively. 
$>50 \%$ of the conidia released daily have not been considered. These conidia would need only to survive until the next leaf wetness event to infect lettuce leaves. Thus, under favorable weather conditions, there is a strong probability that infection can occur after 10:00 $\mathrm{h}$. In this context, favorable conditions refer to leaf wetness, which is the most important variable associated with lettuce downy mildew infection $(10,20)$. According to data analyzed in this study for $1997,1998,2003$, and 2004, 80\% of leaf wetness events occurred between 22:00 and 06:00 h, 7\% between 06:00 and 10:00 h, and 13\% between 10:00 and 22:00 h. Thus, infection by $B$. lactucae could

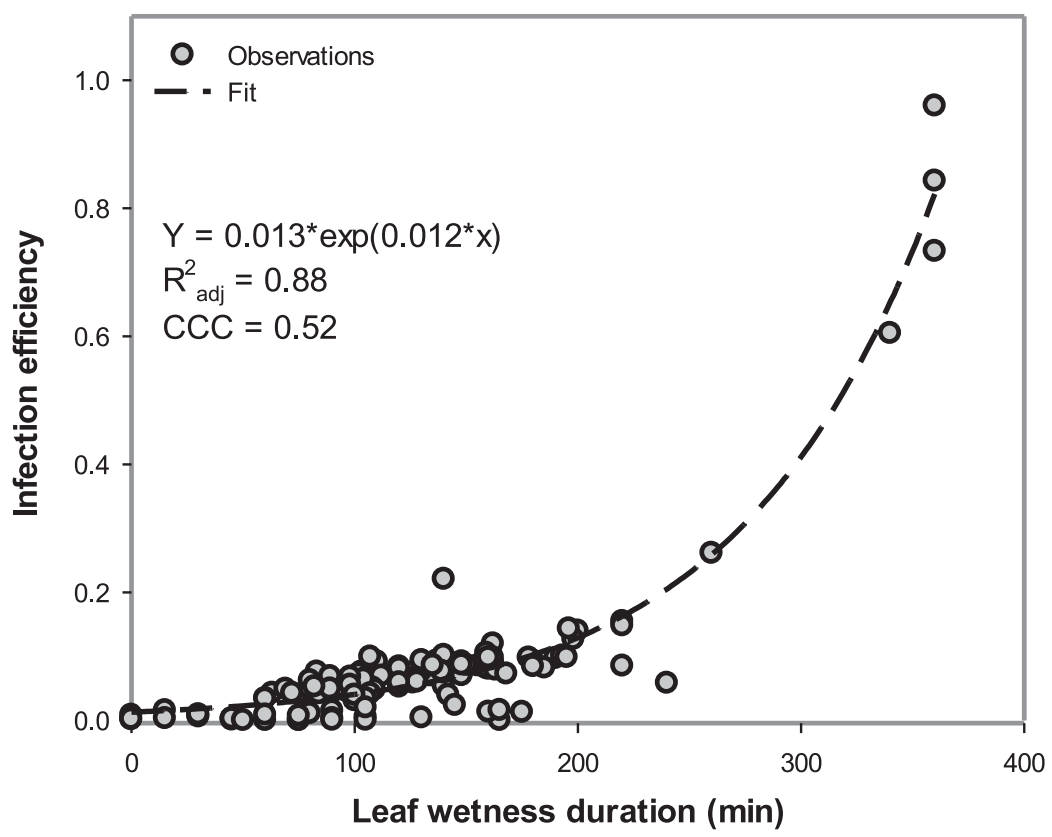

Fig. 8. Relationship between Bremia lactucae infection efficiency (IE) and lettuce leaf wetness duration under field conditions for the data pooled from 4 years (2003, 2004, 2012, and 2013) together. An exponential growth function was fit to the data. IE was defined as the ratio between the number of downy mildew lesions/leaf and airborne conidia concentration. CCC = concordance correlation coefficient, a measure of model appropriateness and goodness of fit (12), and $\mathrm{R}^{2}{ }_{\text {adj }}=$ adjusted coefficient of determination. The study was done in a field at the Agriculture and Agri-Food Canada experimental farm in Ste-Clotilde, Quebec, Canada. Each data point represents the mean number of lesion per leaf and the airborne conidia concentration.

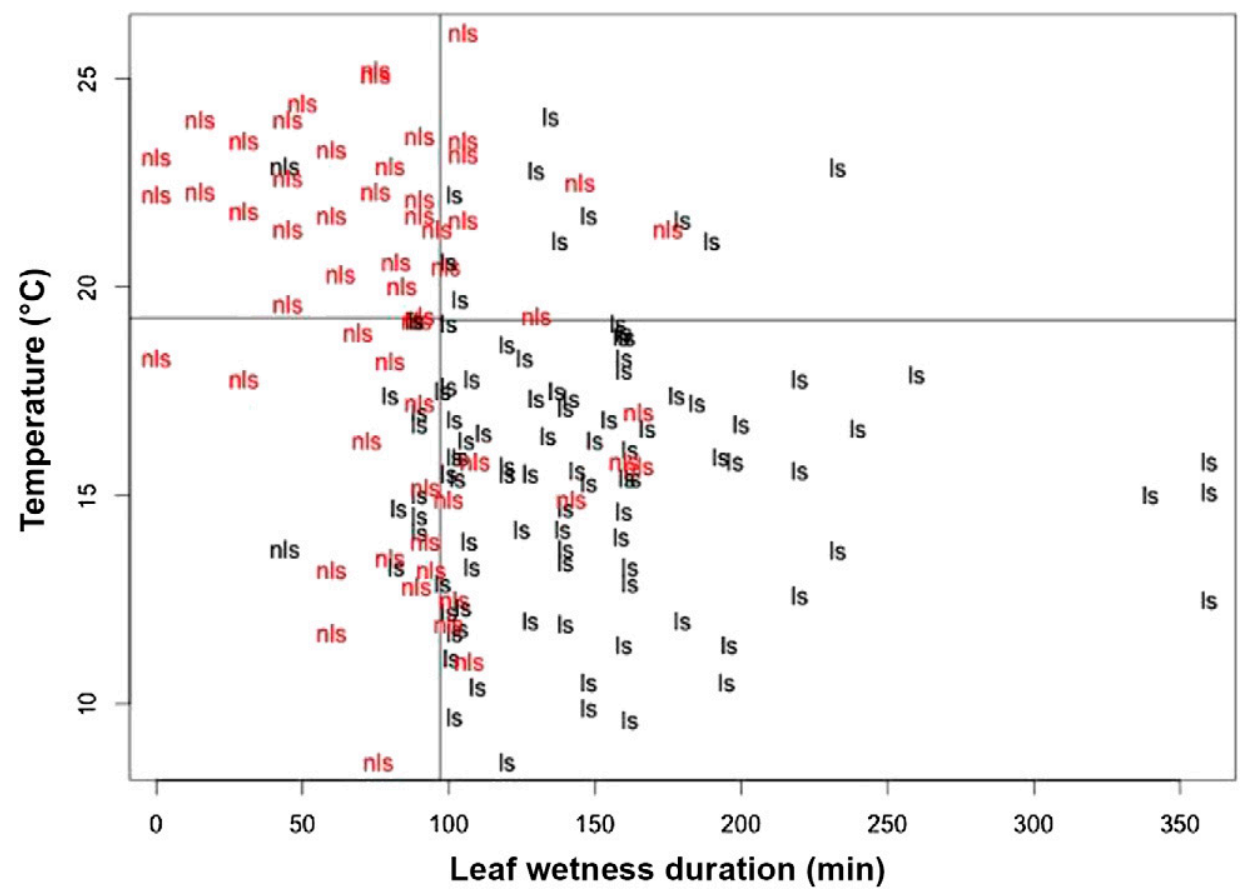

Fig. 9. Occurrence of lettuce downy mildew (Bremia lactucae) lesions (Is) and lack of lesions (nls = no-lesion events) based on leaf wetness duration and average daily air temperature. Data from 4 years $(2003,2004,2012$, and 2013) were pooled. B. lactucae infection efficiency (IE) was defined as the ratio of the number of lesions/leaf to airborne conidia concentration. IE was transformed to a binary variable where IE values $\geq 0.100$ ( 1 lesion/leaf $/ 10$ conidia/ $\mathrm{m}^{3}$ ) were coded as Is and IE values $\leq 0.055$ were coded as nls. IE values between 0.056 and 0.099 were rounded to 0.1. The study was done in a field at the Agriculture and Agri-Food Canada experimental farm in SteClotilde, Quebec, Canada, with $n=154$ trap plants in each field trial. The vertical line represents a threshold based on the leaf wetness duration, which distinguished the Is and nls events. The horizontal line represents a threshold based on the average daily temperature, which distinguished the Is and nls events. 
occur at any time of the day. Also, using only morning leaf wetness as a lettuce downy mildew risk indicator led to $60 \%$ of downy mildew infections being missed. To improve the accuracy and sensitivity of leaf wetness events as a risk indicator of lettuce downy mildew, both morning and evening leaf wetness events should be considered. The results also suggest that, under Quebec weather conditions, infection by $B$. lactucae occurs mostly during the morning and evening. Similar observations have been made in subtropical climates, where conidia were released mostly at dawn and leaves were infected primarily in the morning $(10,16)$. However, Hovius et al. (8) observed that, under Ontario (Canada) weather conditions, lettuce downy mildew did not always develop despite multiple leaf wetness events. Therefore, the limiting factor might be not only leaf wetness duration but also ACC. Scherm et al. (16) suggested that the availability of inoculum must be considered for predicting lettuce downy mildew. Hence, in addition to LWD, ACC should be considered, provided that the relationship between ACC and the severity of infection is known.

Under controlled growth-chamber conditions in this study, the number of lesions/leaf was directly proportional to ACC, and an ACC of 1 conidium $/ \mathrm{m}^{3}$ was sufficient to cause 1 lesion/leaf. Under field conditions, however, the number of lesions/leaf was proportional to ACC up to 15 lesions/leaf, and the maximum number of observed lesions/leaf was 20, probably reflecting the limited amount of healthy leaf area available at such inoculum density. An ACC of 14 conidia $/ \mathrm{m}^{3}$ was required to cause 1 lesion/leaf in the field. For Botrytis leaf blight of onion, the number of lesions/leaf was directly proportional to Botrytis squamosa ACC, and a threshold of 10 to 15 conidia $/ \mathrm{m}^{3}$ was used successfully to rationalize fungicide applications $(3,26)$. Similarly, the results of this study suggest that a Bremia lactucae ACC of 14 conidia $/ \mathrm{m}^{3}$ may be a threshold to time fungicide applications for lettuce downy mildew management in this region. However, to improve the reliability of this threshold, it will be imperative to understand how environmental factors influence infection of lettuce by B. lactucae, for which the IE should provide a reliable response.

In this study, IE increased with increasing LWD but decreased with increasing TPa, although the TPa association with IE was weak (correlation coefficients of $0.00,-0.06,-0.62$, and -0.06 in 2003, 2004, 2012, and 2013, respectively). These results are supported by the findings of Scherm and van Bruggen $(17,19)$ and Wu et al. $(27,29)$, who reported that an increase in infection by B. lactucae resulted from increasing LWD. Wu et al. (27) also concluded that the effect of temperature was minor. Moreover, this study found that the amount of SR recorded in the Quebec region did not have a significant association with IE, except in $2004(P=0.04)$. These results differ from results reported by $\mathrm{Wu}$ et al. (27), who found that a dose of $0.5 \mathrm{MJ} / \mathrm{m}^{2}$ was sufficient to kill most of the B. lactucae conidia, whereas the SR registered over the course of this study ranged from 0.5 and $3.8 \mathrm{MJ} / \mathrm{m}^{2}$. Similarly, Bhaskara Reddy et al. (2) found that $\geq 50 \%$ of B. lactucae spores survived an SR dose of $10 \mathrm{MJ} / \mathrm{m}^{2}$. In summary, LWD seemed to explain most of the variation in IE, and $\mathrm{TPa}$ had a minor effect on IE.

The IE of B. lactucae in this study increased exponentially with increasing LWD. To achieve an IE of 0.1 (1 lesion $/ 10$ conidia $/ \mathrm{m}^{3}$ ), $120 \mathrm{~min}$ of leaf wetness was sufficient. Thus, at an average temperature of $20^{\circ} \mathrm{C}, 2 \mathrm{~h}$ of leaf wetness was sufficient to cause infection by B. lactucae. These results diverge from those reported by Scherm and van Bruggen (19), who established a minimum LWD of $4 \mathrm{~h}$ at temperatures between 5 and $20^{\circ} \mathrm{C}$ for successful infection in California. Therefore, in Quebec lettuce production systems, it may not be sufficient to consider an LWD of 3 to $5 \mathrm{~h}$ after dawn as a lettuce downy mildew risk indicator to initiate fungicide applications. Moreover, an LWD of $>180 \mathrm{~min}$ enabled at least 1 lesion/leaf to develop, even at temperatures between 20 and $26^{\circ} \mathrm{C}$.

This study examined the relationship between the ACC of B. lactucae, the number of lesions/leaf, and selected weather parameters that may significantly influence IE. The results showed that, under controlled conditions, an ACC of 1 conidium $/ \mathrm{m}^{3}$ was sufficient to cause 1 lesion/leaf whereas, under field conditions, an ACC of 10 to 14 conidia $/ \mathrm{m}^{3}$ was required to cause the same disease severity. Consequently, in addition to monitoring leaf wetness periods, real-time monitoring of ACC should help improve lettuce downy mildew control measures for growers. Infection by $B$. lactucae can occur at any time of the day if there is a leaf wetness duration of $\geq 2 \mathrm{~h}$. This study also revealed that, under Quebec weather conditions, both morning and evening leaf wetness events should be used to improve the reliability of LWD as a lettuce downy mildew risk indicator.

To the authors' knowledge, this is the first study to focus on the IE of $B$. lactucae under field conditions, and how environmental factors can influence IE. This study lays the groundwork for future use of an ACC of 10 to 14 conidia/ $\mathrm{m}^{3}$ and an LWD of $2 \mathrm{~h}$ as risk indicators for determining the optimal time to apply downy mildew fungicide. In the Quebec lettuce production area, airborne conidia of B. lactucae could be monitored seasonally to assess the usefulness of these risk indicators. A similar risk indicator has been used successfully in onion crops in the same area to manage Botrytis leaf blight (3). Nevertheless, further research should be done to validate these risk indicators and assess how they can be integrated into management strategies for lettuce downy mildew in this region.

\section{Acknowledgments}

We thank all of the summer students involved in this study; and A. Lavasseur, A. Lefebvre, and R. Bacon for their technical support and advice. This work was supported financially by the Prime-Vert program (sous-volet 11.1) of the Quebec Department of Agriculture, Fisheries and Food (MAPAQ), by Agriculture and Agri-Food Canada, and by Compagnie de Recherche Phytodata Inc.

\section{Literature Cited}

1. Anonymous. 2013. Area, production and farm gate value of vegetables, annual. Statistics Canada Table 001-0013. Online publication. http://www5.statcan.gc.ca/ cansim/a05?lang=eng\&id=0010013\&pattern $=0010013 \&$ searchTypeByValue $=1$ \&p2=35

2. Bhaskara Reddy, M. V., Kushalappa, A. C., and Stephenson, M. M. P. 1996. Effect of solar radiation on the survival of Bremia lactucae spores on lettuce. (Abstr.) Phytoprotection 77:137.

3. Carisse, O., McCartney, H. A., Gagnon, J. A., and Brodeur, L. 2005 Quantification of airborne inoculum as an aid in the management of leaf blight of onion caused by Botrytis squamosa. Plant Dis. 89:726-733.

4. Carisse, O., and Philion, V. 2002. Meteorological factors affecting periodicity and concentration of airborne spores of Bremia lactucae. Can. J. Plant Pathol. 24:184-193.

5. Fall, M. L., Van der Heyden, H., Brodeur, L., Leclerc, Y., Moreau, G., and Carisse, O. 2015. Spatiotemporal variation in airborne sporangia of Phytophthora infestans: Characterization and initiative toward improving potato late blight risk estimation. Plant Pathol. 64:178-190.

6. Fletcher, J. T. 1976. Bremia lactucae, oospores, sporangial dissemination, and control. Ann. Appl. Biol. 84:294-298.

7. Heffer Link, V., Powelson, M. L., and Johnson, K. B. 2002. Oomycetes. American Phytopathological Society, Education. Online publication. Plant Health Instruct.

8. Hovius, M. H. Y., McDonald, M. R., Carisse, O., and Philion, V. 2007. Field evaluation of weather-based spray programs for the control of downy mildew of lettuce (Lactuca sativa), caused by Bremia lactucae, in Quebec and Ontario. Can. J. Plant Pathol. 29:9-17.

9. Hughes, G. 2011. Applications of Information Theory to Epidemiology. American Phytopathological Society, St. Paul, MN.

10. Kushalappa, A. C. 2001. BREMCAST: Development of a system to forecast risk levels of downy mildew on lettuce (Bremia lactucae). Int. J. Pest Manage. 47:1-5.

11. Lamour, K., and Kamoun, S. 2009. Oomycete Genetics and Genomics: Diversity, Interactions and Research Tools. Wiley-Blackwell, John Wiley \& Sons, Hoboken, NJ.

12. Madden, L. V., Hughes, G., and van den Bosch, F. 2007. The Study of Plant Disease Epidemics. American Phytopathological Society, St. Paul, MN.

13. Nordskog, B., Gadoury, D. M., Seem, R. C., and Hermansen, A. 2007. Impact of diurnal periodicity, temperature, and light on sporulation of Bremia lactucae. Phytopathology 97:979-986.

14. Olanya, O. M., Honeycutt, C. W., Tschöepe, B., Kleinhenz, B., Lambert, D. H., and Johnson, S. B. 2012. Effectiveness of SIMBLIGHT1 and SIMPHYT1 models for predicting Phytophthora infestans in the north-eastern United States. Arch. Phytopathol. Plant Prot. 45:1558-1569.

15. Ripley, B. 2015. Classification and regression trees version 1.0-35. R packages The Comprehensive R Archive Network (cran). Online publication. http://cran. r-project.org/web/packages/tree/tree.pdf

16. Scherm, H., Koike, S. T., Laemmlen, F. F., and van Bruggen, A. H. C. 1995 Field evaluation of fungicide spray advisories against lettuce downy mildew (Bremia lactucae) based on measured or forecast morning leaf wetness. Plant Dis. 79:511-516.

17. Scherm, H., and van Bruggen, A. H. C. 1993. Response surface models for germination and infection of Bremia lactucae, the fungus causing downy mildew of lettuce. Ecol. Model. 65:281-296. 
18. Scherm, H., and van Bruggen, A. H. C. 1993. Sensitivity of simulated dew duration to meteorological variations in different climatic regions of California. Agric. For. Meteorol. 66:229-245.

19. Scherm, H., and van Bruggen, A. H. C. 1994. Effects of fluctuating temperatures on the latent period of lettuce downy mildew (Bremia lactucae). Phytopathology 84:853-859.

20. Scherm, H., and van Bruggen, A. H. C. 1994. Weather variables associated with infection of lettuce by downy mildew (Bremia lactucae) in coastal California. Phytopathology 84:860-865.

21. Shurtleff, M. C., and Averre, C. W., III. 1997. Glossary of Plant-Pathological Terms. American Phytopathological Society, St. Paul, MN.

22. Simko, I., Atallah, A. J., Ochoa, O. E., Antonise, R., Galeano, C. H., Truco, M. J., and Michelmore, R. W. 2013. Identification of QTLs conferring resistance to downy mildew in legacy cultivars of lettuce. Online publication. Sci. Rep. 3: Article number 2875 .

23. Su, H., van Bruggen, A. H. C., and Subbarao, K. V. 2000. Spore release of Bremia lactucae on lettuce is affected by timing of light initiation and decrease in relative humidity. Phytopathology 90:67-71.
24. Su, H., van Bruggen, A. H. C., Subbarao, K. V., and Scherm, H. 2004 Sporulation of Bremia lactucae affected by temperature, relative humidity, and wind in controlled conditions. Phytopathology 94:396-401.

25. Tchervenivanova, E. 1995. Development of a model to predict sporulation of Bremia lactucae in lettuce. M.Sc. thesis, McGill University, Montreal, QC, Canada.

26. Van der Heyden, H., Carisse, O., and Brodeur, L. 2012. Comparison of monitoring based indicators for initiating fungicide spray programs to control Botrytis leaf blight of onion. Crop Prot. 33:21-28.

27. Wu, B. M., Subbarao, K. V., and van Bruggen, A. H. C. 2000. Factors affecting the survival of Bremia lactucae sporangia deposited on lettuce leaves. Phytopathology 90:827-833.

28. Wu, B. M., van Bruggen, A. H. C., Subbarao, K. V., and Pennings, G. G. H 2001. Spatial analysis of lettuce downy mildew using geostatistics and geographic information systems. Phytopathology 91:134-142.

29. Wu, B. M., van Bruggen, A. H. C., Subbarao, K. V., and Scherm, H. 2002. Incorporation of temperature and solar radiation thresholds to modify a lettuce downy mildew warning system. Phytopathology 92:631-636. 